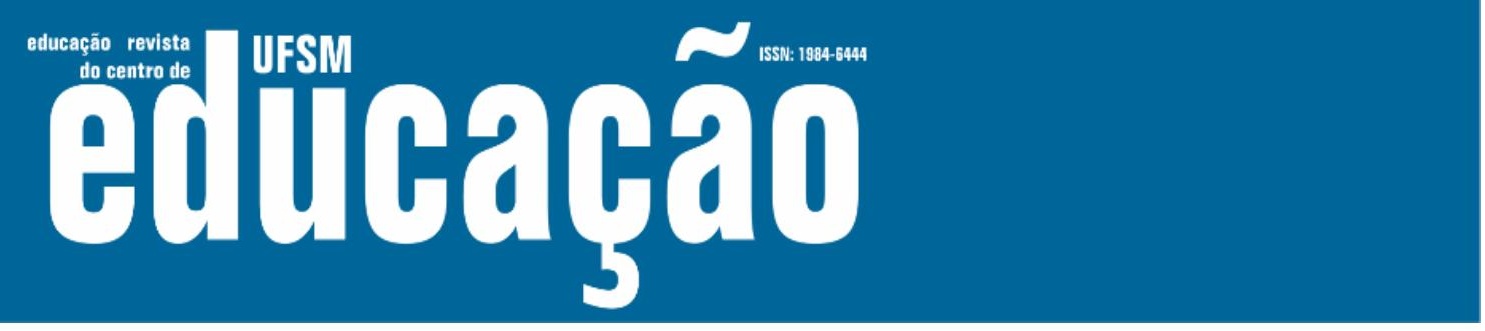

ISSN: 1984-6444 | http://dx.doi.org/10.5902/1984644435982

\title{
A educação e o processo de reestruturação produtiva: a incapacidade civilizatória sob a égide do Capital
}

\author{
Education and the process of production restructuring: the civilizing \\ inability under the aegis of Capital
}

\begin{abstract}
Marco Antonio De Oliveira Gomes
Professor doutor na Universidade Estadual de Maringá. Maringá, Paraná, Brasil. marcooliveiragomes@yahoo.com - https://orcid.org/0000-0002-2397-5615
\end{abstract}

Marilsa Miranda De Souza

Professora doutora na Universidade Federal de Rondônia, Porto Velho, Rondônia, Brasil. msmarilsa@hotmail.com - https://orcid.org/0000-0001-9043-7510

\section{Ana Paula Aires Rodrigues}

Mestranda na Universidade Estadual de Maringá. Maringá, Paraná, Brasil ana_aires1@outlook.com - http://orcid.org/0000-0001-9359-6779

Recebido em 10 de dezembro de 2018

Aprovado em 25 de julho de 2019

Publicado em 29 de março de 2020

\section{RESUMO}

O presente artigo tem como objetivos investigar os limites da promessa de inserção dos trabalhadores em um mercado cada vez mais competitivo e discutir as possíveis implicações dessa inserção para a classe trabalhadora no contexto atual. Trata-se de um estudo bibliográfico-documental, no qual como questão metodológica, torna-se imperativo analisar as mudanças advindas no interior da produção e suas conexões com a educação escolar. Os documentos analisados foram obtidos por meio das seguintes instituições oficiais: a Agência de notícias do Instituto Brasileiro de Geografia e Estatística-IBGE e do Censo de Ensino Superior de 2014. Além disso, são apresentados dados existentes no relatório Tendências Globais de Emprego para a Juventude 2017, da Organização Internacional do Trabalho-OIT, entre outros considerados pertinentes. A análise aqui apresentada está subsidiada na epistemologia marxiana, já que essa nos possibilita a compreensão do princípio da totalidade, o que implica pensar as múltiplas relações existentes neste contexto e as vinculações objetivas dessas com o objeto da análise. Entendemos que os acontecimentos históricos em questão são expressão dos desafios enfrentados pelos trabalhadores diante das contradições nas relações de trabalho engendradas no modo de produção capitalista. Ressalta-se com base nos dados levantados, que o ideário da educação escolar como panaceia para a resolução da desigualdade social, tratase em última instância, de uma falácia teórica produzida no bojo do próprio sistema.

Palavras-chave: Trabalho; Educação; Reestruturação produtiva do capital. 


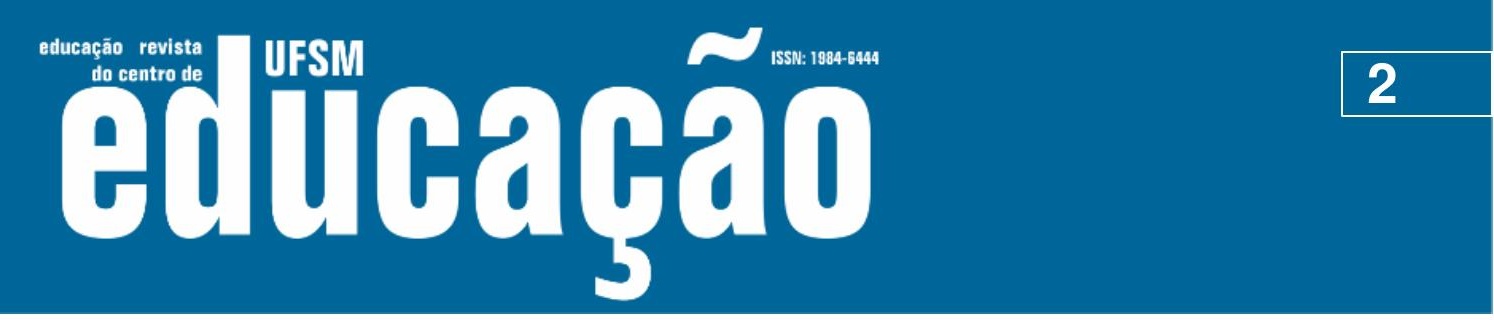

ISSN: 1984-6444 | http://dx.doi.org/10.5902/1984644435982

\begin{abstract}
Current study investigates the promised insertion limits of workers in an increasingly competitive market and discusses possible implication of such insertion for laborers within a contemporary context. Changes within production and its connections with schooling are analyzed in present bibliographic and documental analysis. Analyzed documents hailed from official institutions, such as the news agency of the Brazilian Institute of Geography and Statistics (IBGE) and the 2014 Higher Education Census, coupled to data from the ILO's report Global Employment Trends for Youth 2017 and others. Since it provides an understanding of the principle of totality, analysis is based on Marxist epistemology. It implies in multiple relationships within this context and their objective links to the analysis's aims. There is a conviction that historical events under analysis are the expression of challenges faced by workers in the wake of contradictions in labor relationships formed within capitalist production. Data underscore that the best schooling education, considered as a panacea for the eradication of social inequality, is ultimately a theoretical fallacy fabricated within the system.
\end{abstract}

Keywords: Job; Education; Productive restructuring of capital.

\title{
Introdução
}

As mudanças ocorridas no âmbito da produção e a correlação de forças entre burguesia e proletariado foram determinantes para a constituição de leis que regulassem a relação entre capital e trabalho ao longo do século $X X$. Entre avanços e recuos, a legislação trabalhista brasileira alcançou sua maior amplitude com a promulgação da Constituição Federal de 1988. Além dos direitos normatizados pela Consolidação das Leis do Trabalho-CLT, outros foram instituídos, tais como a redução da jornada de trabalho de 48 para 44 horas semanais, o abono de 1/3 (um terço) das férias, entre outros.

Porém, observa-se nos últimos anos um processo de ofensiva burguesa com vistas à supressão dos direitos conquistados pelos trabalhadores no Brasil. Por isso, em um momento que vivenciamos uma crise estrutural do capitalismo, que arrasta milhares de trabalhadores para condições de subemprego, trabalho temporário ou mesmo para a miséria absoluta, é fundamental analisar os desdobramentos da reestruturação produtiva e seus vínculos com as reformas propostas para a educação. 


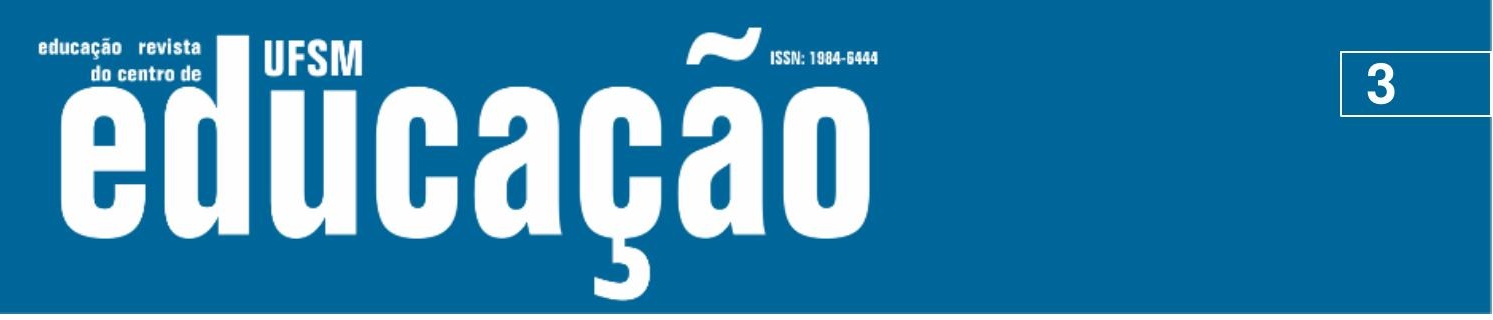

ISSN: 1984-6444 | http://dx.doi.org/10.5902/1984644435982

Diante do exposto, o presente artigo objetiva, por meio de uma pesquisa bibliográfica e documental, investigar os limites da promessa de inserção dos trabalhadores em um mercado cada vez mais competitivo e discutir as possíveis implicações dessa inserção para a classe trabalhadora. Para atingirmos tais propósitos, como questão metodológica torna-se imperativo analisar as mudanças advindas no interior da produção e suas conexões com a educação escolar. Tomamos como diretriz de nossos estudos os trabalhos de Hobsbawm (1995), Marx e Engels (2001), entre outros autores.

A partir da perspectiva epistemológica do materialismo histórico e dialético, qualquer fenômeno, incluindo a educação, não pode ser concebido acima das relações engendradas pelo homem na produção da existência. De tal modo, não existe, para Marx, o primado das ideias na vida social. Assim, as ideias não se explicam por si mesmas. Dentro da perspectiva marxiana, há claramente uma concepção alicerçada na centralidade do trabalho, enquanto atividade promotora de transformação do homem e da natureza na produção e reprodução da vida social e, concomitantemente, a negação da reflexão filosófica abstrata.

A produção das ideias, de representações e da consciência está em primeiro
lugar direta e intimamente ligada à atividade material e ao comércio material
dos homens, é a linguagem da vida real. São os homens que produzem as
suas representações, as suas ideias, etc., mas os homens reais, atuantes e
tais como foram condicionados por um determinado desenvolvimento das
suas forças produtivas e do modo de relações que lhe corresponde, incluindo
até as formas mais amplas que estas possam tomar. A consciência nunca
pode ser mais que o Ser consciente; e o Ser dos homens é o seu processo
de vida real. (MARX; ENGELS, 2001, p. 17). Nesse sentido, temos como propósito identificar as diferenças entre as proclamações presentes nos discursos oficiais, que apontam abstratamente para a inserção dos egressos dos bancos escolares no mercado, e o que ocorre de fato na prática. Em consonância com a epistemologia marxiana é fundamental diferenciar entre fatos abstratos sem conexão com o real e o que é comprovável por meio da prática social. 


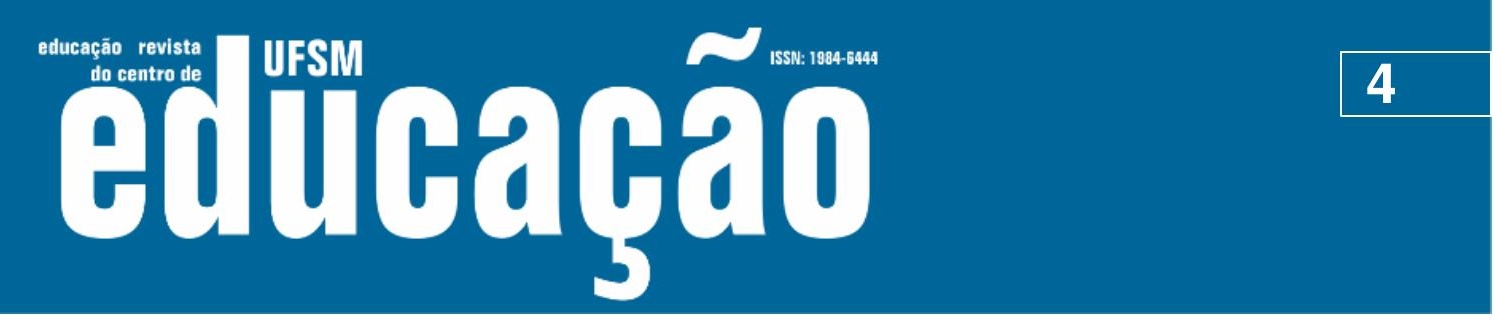

ISSN: 1984-6444 | http://dx.doi.org/10.5902/1984644435982

\section{A reestruturação produtiva e a contraofensiva do capital}

Para exata análise do processo de reestruturação produtiva do capital faz-se necessário compreender o cenário que se configurou no período pós Segunda Guerra Mundial (1930-45). Na condição de potência capitalista hegemônica, os Estados Unidos da América (EUA) assumiram um papel determinante na constituição do sistema monetário criado em 1944, em Bretton Woods, que definiu as diretrizes da economia global após o término da Segunda Guerra Mundial, além da criação de instituições econômicas, como o Fundo Monetário Internacional (FMI), o Banco Mundial (BIRD) e o Acordo Geral sobre Tarifas e Comércio (GATT), que constituíramse em instrumentos dos interesses imperialistas. Era o início da era de "ouro" do capitalismo.

O mundo industrial, claro, se expandia por toda a parte: nas regiões capitalistas e socialistas e no "Terceiro Mundo". No velho Ocidente, houve impressionantes exemplos de revolução industrial, como a Espanha e a Finlândia. No mundo do "socialismo existente", países predominantes agrários como a Bulgária e a Romênia ganharam expressivos setores industriais. [...] A economia mundial, portanto, crescia a uma taxa explosiva. Na década de 1960, era claro que jamais houvera algo assim. A produção mundial de manufaturas quadruplicou entre o início de 1950 e o início da década de 1970, e, o que é mais ainda impressionante, o comércio mundial de produtos manufaturados aumentou dez vezes. (HOBSBAWM, 1995, p. 256-257)

Prevaleceu nesse momento o Estado de bem-estar social como um projeto que objetivava recuperar as economias capitalistas destruídas pela Segunda Guerra Mundial. Os chamados anos "dourados" do capitalismo materializaram-se na expansão industrial, nas oportunidades de emprego e em políticas públicas de proteção social. Porém, faz-se necessário lembrar que as benesses do capitalismo não foram universalizadas. Permanecia intacta sua essência de dominação de classe e o apetite insaciável do imperialismo.

Ainda no cenário do período pós-guerra, prevaleceu o padrão de produção alicerçado no taylorismo-fordismo, que se caracterizava pela racionalização produtiva, separando a concepção e execução do trabalho, com propósitos ao disciplinamento da força de trabalho e ampliação da produção em um menor espaço de tempo. Em outros termos, o fordismo assentava-se no processo de produção em massa 


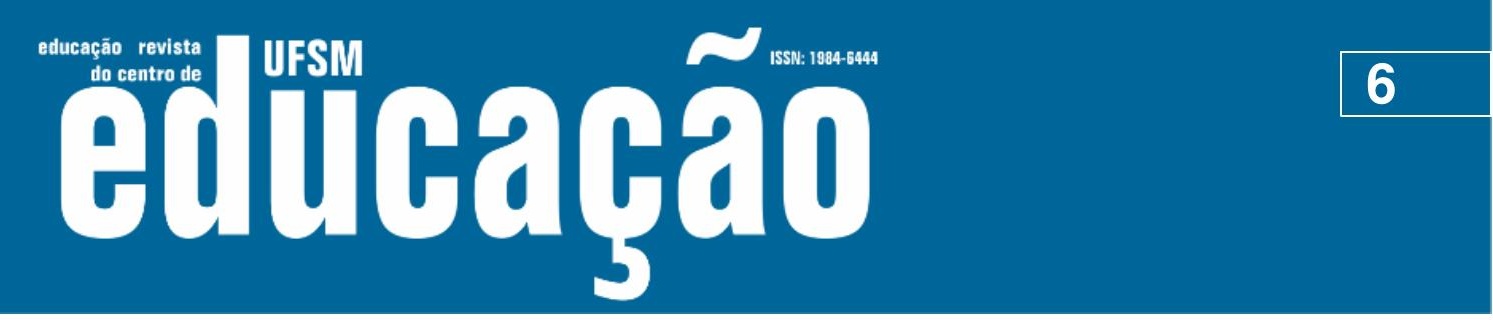

ISSN: 1984-6444 | http://dx.doi.org/10.5902/1984644435982

Como desdobramentos das mudanças ocorridas nas formas de produção, em um cenário marcado pelo crescente desemprego, a exigência sobre os trabalhadores torna-se cada vez maior.

\begin{abstract}
A tragédia histórica das Décadas de Crise foi a de que a produção agora dispensava visivelmente seres humanos mais rapidamente do que a economia de mercado gerava novos empregos para eles. Além disso, esse processo foi acelerado pela competição global, pelo aperto financeiro dos governos, que - direta ou indiretamente - eram os maiores empregadores individuais, e não menos, após 1980 , pela então predominante teologia do livre mercado que pressionava em favor da transferência de emprego para formas empresariais de maximização de lucros, sobretudo de empresas privadas que, por definição, não pensavam em torno de outro interesse além do seu próprio pecuniário. [...] O declínio dos sindicatos, enfraquecidos tanto pela depressão econômica quanto pela hostilidade de governos neoliberais, acelerou esse processo, pois a produção de empregos era uma de suas funções mais estimadas. (HOBSBAWM, 1995, p. 404)
\end{abstract}

A crise estrutural que se configurou interrompeu o crescimento acelerado das décadas anteriores. A recessão era diagnosticada por inúmeros intelectuais como expressão da ineficiência do Estado e do excessivo poder dos sindicatos. Nesses termos, a reestruturação produtiva engendrou transformações no âmbito do Estado e das relações entre capital e trabalho.

Diante da crise estrutural que, tomou grandes proporções nas mais diferentes nações do globo, os postulados de Milton Friedman (1988) e Friedrich Hayek (2010) ganharam destaque ao defenderem o imperativo da redução do Estado para as questões sociais. No cenário marcado pela paralisação econômica e pelo crescente desemprego, o mercado era apresentado como alternativa para a superação da crise. Abriam-se as portas para as "novas" proposições destinadas às reformas neoliberais. Dessa forma, intensificaram-se as pressões burguesas por austeridade orçamentária, o que tem se materializado no Brasil com corte de despesas para áreas sociais. Ainda que contemporaneamente o desmantelamento do Estado esteja fora de cogitação em função do próprio caráter de classe, Piketty (2014, p. 613) ressalta que nos EUA "certos grupos minoritários, mas significativos, questionam até mesmo a existência de qualquer programa social federal, aliás de qualquer programa social.

No Brasil também é possível encontrar proposições que, tal qual os grupos minoritários identificados por Piketty (2014), questionam programas sociais. Para 


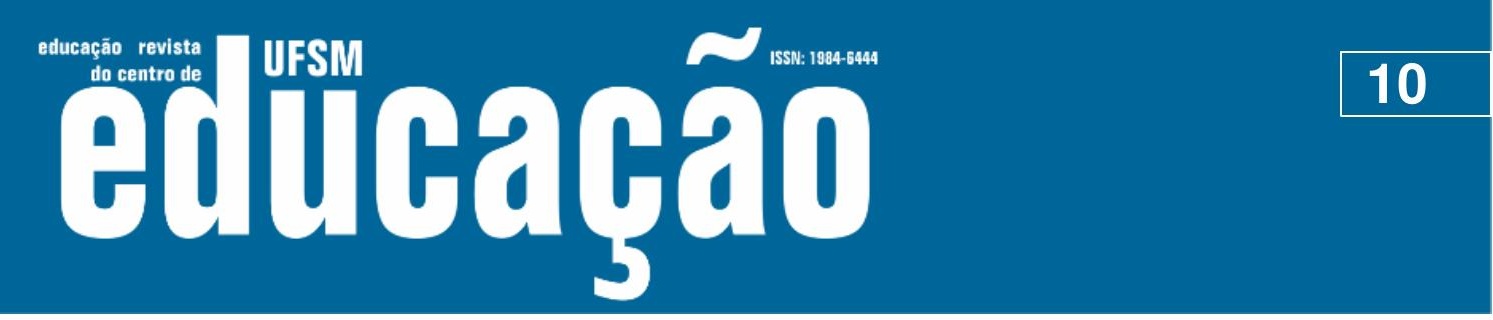

ISSN: 1984-6444 | http://dx.doi.org/10.5902/1984644435982

Passou-se de uma lógica da integração em função de necessidades e demandas de caráter coletivo (a economia nacional, a competitividade das empresas, a riqueza social etc.) para uma lógica econômica estritamente privada e guiada pela ênfase nas capacidades e competências que cada pessoa deve adquirir no mercado educacional para atingir uma melhor posição no mercado de trabalho. (GENTILI, 2004, p. 51)

Desta forma, o trabalhador deve escolher a "mercadoria" educacional que the convém para vender sua força de trabalho no mercado. Em síntese, trata-se de educar para o desemprego, incutindo no trabalhador a culpa pelo sucesso ou fracasso na conquista de uma colocação no mercado de trabalho.

Morta definitivamente a promessa do pleno emprego, restará ao indivíduo (e não ao Estado, às instâncias de planejamento ou às empresas) definir suas próprias opções, suas próprias escolhas que permitam (ou não) conquistar uma posição mais competitiva no mercado de trabalho. A desintegração da promessa integradora deixará lugar à difusão de uma nova promessa, agora sim, de caráter estritamente privado: a promessa da empregabilidade. (GENTILI, 2004, p. 51)

É interessante notar que apesar das mudanças aparentes, a Teoria do Capital Humano não muda em sua essência: a educação continua sendo apresentada como "solução" dos problemas nacionais. No entanto, como os propósitos não são atingidos e as desigualdades permanecem, a responsabilidade recai sobre os próprios indivíduos, considerados incapazes, ou sobre o sistema escolar, entendido como ineficiente. Por isso, não causa estranheza a permanência de discursos aparentemente diferenciados, mas que retomam a tese do poder transformador da educação. É o que se pode verificar, por exemplo. Na página oficial do Ministério Público do estado de Rondônia, por exemplo, pode-se ler:

É inegável o poder universal de transformação que a Educação de qualidade
pode realizar, porém é fundamental que este tema saia do plano da retórica,
circulando nos gabinetes de governo, invadindo as rodas de empresários e
passe a integrar a agenda de todo cidadão. A Educação é a saída para mudar
esse cenário: hoje, sabe-se que o caminho não é crescer e investir em
Educação, mas educar para crescer. Todos os países que passaram de
subdesenvolvidos a desenvolvidos investiram muito em Educação, gerando
a base para o progresso. Sabe-se que na Finlândia, na Coreia do Sul e na
Espanha a prioridade à Educação foi absoluta, e são bons exemplos de uma
transformação radical no cenário econômico mundial ao longo das últimas
décadas. (MINISTÉRIO PÚBLICO DO ESTADO DE RONDÔNIA, 2013, s/p). 


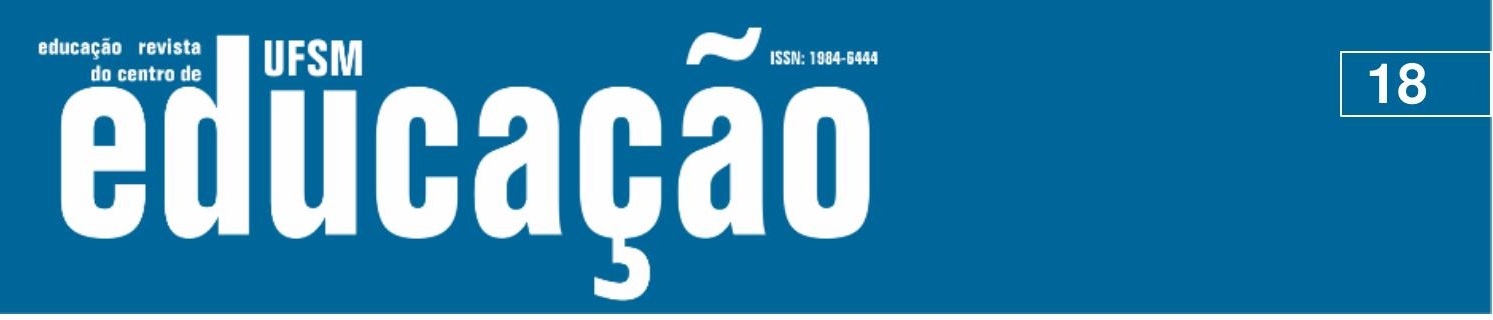

ISSN: 1984-6444 | http://dx.doi.org/10.5902/1984644435982

\section{Referências}

AGÊNCIA DE NOTÍCIAS DO INSTITUTO BRASILEIRO DE GEOGRAFIA E ESTATÍSTICA-IBGE. Desemprego volta a crescer com 13,1 milhões de pessoas em busca de ocupação. Rio de Janeiro, 2018. Disponível em: https://agenciadenoticias.ibge.gov.br/agencia-noticias/2012-agencia-denoticias/noticias/20674-desemprego-volta-a-crescer-com-13-1-milhoes-de-pessoasem-busca-de-ocupacao. Acesso em: 14 de outubro de 2018.

ANTUNES, Ricardo. O privilégio da servidão: o novo proletariado de serviços na era digital. São Paulo: Boitempo, 2018.

ARAÚJO, Ronaldo Marcos de Lima. As novas "qualidades pessoais" requeridas pelo capital. Trabalho \& Educação. Núcleo de Estudos sobre Trabalho e Educação/UFMG, Belo Horizonte, № 5, p. 18-33, 1999. Disponível em: https://seer.ufmg.br/index.php/trabedu/article/view/7535. Acesso em: 01 de dezembro de 2018.

CARDOSO, Fernando Henrique. Apresentação. In: BRASIL. Ministério da Administração Federal e Reforma do Estado - MARE. Plano Diretor da Reforma do Aparelho do Estado. Brasília, DF: novembro de 1995.

CHAVES, Eduardo Oscar Epprecht e Machado de Campos. O liberalismo na política, economia e sociedade e suas implicações para a educação: uma defesa. In: LOMBARDI, José Claudinei; SANFELICE (orgs.) Liberalismo e educação em debate. Campinas: Autores Associados, 2007.

COLARES, Anselmo Alencar; GOMES, Marco Antonio de Oliveira. A. O.; COLARES, Maria Lília Imbiriba Sousa. Educação Escolar e Trabalho: desmitificando sua propalada integração. Revista HISTEDBR On-line, Campinas, n. 57, p. 165-179, jun. 2014.

Disponível em: https://periodicos.sbu.unicamp.br/ojs/index.php/histedbr/article/view/8640410. Acesso em: 28 de novembro de 2018

FRIEDMAN, Milton. Capitalismo e Liberdade. São Paulo: Nova Cultural, 1988.

FRIGOTTO, Gaudêncio. Educação e a crise do capitalismo real. São Paulo: Cortez, 2000.

FRIGOTTO, Gaudêncio. Delírios da razão: crise do capital e metamorfose conceitual no campo educacional. In: GENTILI, Pablo. (Org.). Pedagogia da exclusão: crítica ao neoliberalismo em educação. 12. ed. Petrópolis: Vozes, 2005, p. 77 - p. 108.

FRIGOTTO, Gaudêncio. A produtividade da escola improdutiva: um (re)exame das relações entre educação e estrutura econômico-social e capitalista. São Paulo: Cortez, 1984. 


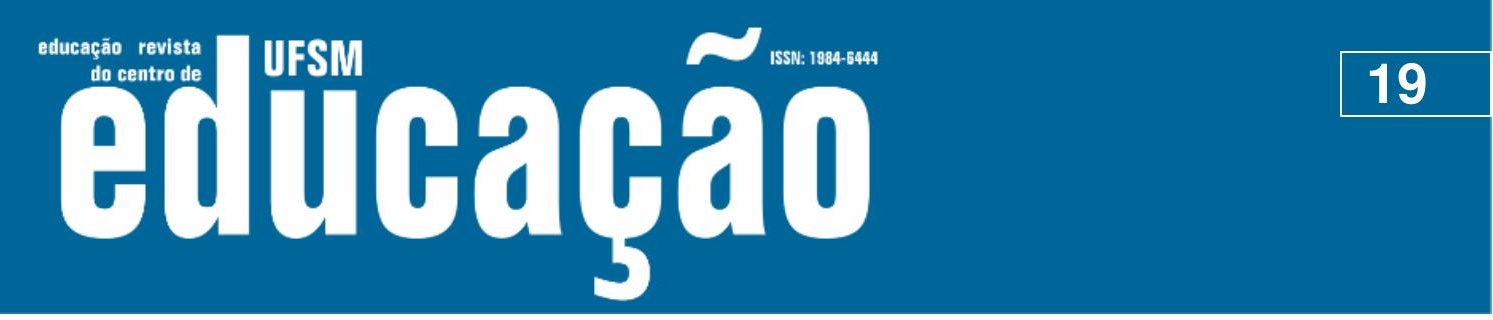

ISSN: 1984-6444 | http://dx.doi.org/10.5902/1984644435982

GENTILI, Pablo. Três teses sobre a relação trabalho e educação em tempos neoliberais. In: LOMBARDI, J.C.; SAVIANI, D.; SANFELICE, J.L. (orgs.) Capitalismo, trabalho e educação. Campinas: Autores Associados, 2004, p. 43 - p. 59.

HAYEK. Friedrich August von. O caminho da servidão. São Paulo: Instituto Ludwig von Mises Brasil, 2010.

HOBSBAWM, Eric. Era dos Extremos: o breve século XX (1914/1991). São Paulo: Companhia das Letras. 1995.

LIPOVETSKY, Gilles. A sociedade da decepção. Barueri: Manole, 2007.

LOMBARDI, José Claudinei. Crise Capitalista e Educação Brasileira. In: LOMBARDI, José Claudinei. Crise capitalista e educação brasileira. Uberlândia, MG: Navegando Publicações, 2016.

MARX, Karl; ENGELS, Friedrich. A Ideologia Alemã. São Paulo: Martins Fontes, 2001.

MINISTÉRIO PÚBLICO DO ESTADO DE RONDÔNIA. A Educação X Problemas Sociais. In: GATTO, Liccia. A Educação X Problemas Sociais. Coluna opinião. Gazeta de Alagoas. Maceió, 19 de dezembro de 2013. Disponível em: https://www.mpro.mp.br/noticia/-/ver-noticia/10861\#.XAhi62hKjlU. Acesso em: 03 de dezembro de 2018.

NETTO, José Paulo; BRAZ, Marcelo. Economia Política: uma introdução crítica. (Biblioteca básica de serviço social; v.1) São Paulo: Cortez, 2012.

PIKETTY, Thomas. O capital no século XXI. Rio de Janeiro: Intrínseca, 2014.

POCHMANN, Marcio. A metrópole do trabalho. São Paulo: Brasiliense, 2001.

ORGANIZAÇÃO INTERNACIONAL DO TRABALHO. Tendências Globais de Emprego para juventude 2017: caminhos para um futuro melhor de trabalho. Genebra, 2017. Relatório. Disponível em: https://www.ilo.org/global/publications/books/globalemployment-trends/WCMS_598669/lang--pt/index.htm. Acesso em: 01 de dezembro de 2018.

ORGANIZAÇÃO INTERNACIONAL DO TRABALHO. Estimativas Globais da Escravidão Moderna: Trabalho Forçado e Casamento Forçado. In: Tendências Globais de Emprego para juventude 2017: caminhos para um futuro melhor de trabalho. Genebra, 2017. Genebra, 2017. Relatório. Disponível em: https://www.ilo.org/global/publications/books/global-employmenttrends/WCMS_598669/lang--pt/index.htm Acesso em: 03 de dezembro de 2018.

SCHULTZ, Theodore William. O capital humano: investimentos em educação e pesquisa. Rio de Janeiro: Zahar Editores, 1973. 


\section{usm

ISSN: 1984-6444 | http://dx.doi.org/10.5902/1984644435982

TEIXEIRA, Ana. Trabalho, tecnologia e educação: algumas considerações. Trabalho e Educação. Belo Horizonte, NETE/UFMG, no 4, p. 161-184, 1998. Disponível em: https://seer.ufmg.br/index.php/trabedu/article/view/7494/5802. Acesso em: 01 de dezembro de 2018.

ZARIFIAN, Philippe. Uma crise inédita do capitalismo, tanto em suas características quanto em sua gravidade: análise e perspectivas. Estudos avançados, vol.23 no 65. São Paulo, 2009.

ZIEGLER, Jean. Genocídio silencioso: um sexto da humanidade não tem o que comer. Diário Liberdade. Jornal Trabalhadores Sem Terra. Página Global, 2011. Entrevista. Disponível em: https://www.diarioliberdade.org/mundo/laboral-economia/19878genocidio-silencioso-um-sexto-da-humanidade-nao-tem-o-que-comer.html. Acesso em: 28 de fevereiro de 2018.

ZYLBERSTAJN, Hélio. Palestra Intitulada: "O Mercado de Trabalho e a sua Carreira", proferida no dia 25 de maio de 2016, no anfiteatro Altino Antunes da Universidade de São Paulo-USP. São Paulo, 2016. (Informação verbal)

\section{Correspondência}

Marco Antonio De Oliveira Gomes - Universidade Estadual de Maringá. Av. Colombo, 5790, Zona 7, CEP 87020-900, Maringá, Paraná, Brasil.

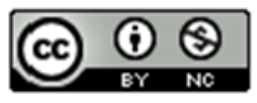

This work is licensed under a Creative Commons Attribution-NonCommercial 4.0 International (CC BY-NC 4.0)

\section{Notas}

\footnotetext{
${ }^{1}$ Referência ao mito de Sísifo. Ver: CAMUS, Albert. O mito de Sísifo: ensaio sobre o absurdo. Record: Rio de Janeiro, 2018.

${ }^{2}$ Informação verbal: Palestra Intitulada "O Mercado de Trabalho e a sua Carreira”, proferida no dia 25 de maio de 2016, no anfiteatro Altino Antunes da Universidade de São Paulo-USP.
} 